\title{
A Community-Based Assessment of Hypertension and Some Other Cardiovascular Disease Risk Factors in Ngaoundéré, Cameroon
}

\author{
Olivier Pancha Mbouemboue, ${ }^{1,2}$ Diana Derew, ${ }^{1}$ \\ Jacques Olivier Ngoufack Tsougmo, ${ }^{1,2}$ and Marcel Tangyi Tamanji ${ }^{3,4}$ \\ ${ }^{1}$ Department of Biomedical Sciences, Faculty of Science, University of Ngaoundéré, P.O. Box 454, Ngaoundéré, Cameroon \\ ${ }^{2}$ General Medicine Service, Ngaoundéré Regional Hospital, P.O. Box 45, Ngaoundéré, Cameroon \\ ${ }^{3}$ Clinical Laboratory Service, Ngaoundéré Regional Hospital, P.O. Box 45, Ngaoundéré, Cameroon \\ ${ }^{4}$ Faculty of Science, University of Buea, P.O. Box 63, Buea, Cameroon \\ Correspondence should be addressed to Olivier Pancha Mbouemboue; olivier_pancha@yahoo.fr
}

Received 11 September 2016; Accepted 15 November 2016

Academic Editor: Claudio Borghi

Copyright ( 2016 Olivier Pancha Mbouemboue et al. This is an open access article distributed under the Creative Commons Attribution License, which permits unrestricted use, distribution, and reproduction in any medium, provided the original work is properly cited.

\begin{abstract}
Background and Objective. Cardiovascular diseases are primary causes of death worldwide with well documented risk factors whose varying impacts added to the complexity in CVD management dictate the need for region-specific studies. We aimed at investigating the interactions between CVD risk factors and hypertension in Ngaoundéré. Methods. A cross-sectional survey was carried out from March to August 2014. Sociodemographic, fasting blood glucose, blood pressure, and anthropometric data were recorded. Statistical analyses were carried out using SAS software version 9.1. Results. 700 adults resident in Ngaoundéré for at least two years consented and were included in the survey. Abdominal obesity, physical inactivity, and hypertension were the dominant risk factors recording $51.1 \%, 35.4 \%$, and $20.4 \%$, respectively. The prevalence of hyperglycaemia, tobacco consumption, obesity, and alcohol consumption was $5.6 \%, 8.3 \%, 9.6 \%$, and $18.1 \%$, respectively. Advanced age, hyperglycaemia, a divorced marital status, and alcohol consumption were independent determinants of high blood pressure. Conclusion. Physical inactivity, abdominal obesity, and hypertension were the most prevalent CVD risk factors, and the role of advanced age and hyperglycaemia in the occurrence of high blood pressure was reiterated. Health programs need to focus on effective screening, prevention, and control of CVDs in the Adamawa Region and Cameroon at large.
\end{abstract}

\section{Introduction}

Noncommunicable diseases (NCDs) represent an essential public health problem worldwide and their increasing occurrence in Africa simultaneously with infectious diseases is of particular importance $[1,2]$. Generally, NCDs account for approximately two-thirds of the global mortality with diabetes and cardiovascular pathologies among other diseases taking the lead $[3,4]$. NCDs and cardiovascular diseases (CVDs) contribute, respectively, to $82 \%$ and $37 \%$ of all the deaths under the age of 70 in developing countries [4]. CVDs represent the first cause of mortality and are responsible for about a third of all deaths worldwide, four-fifths of which occur in developing countries $[4,5]$. In Cameroon, CVDs account for $11 \%$ of total mortality and central to this problem are associated risk factors defined by WHO as any attribute, characteristic, or exposure of an individual that increases the likelihood of developing the disease [6]. Consequently, CVDs prevention and the reduction of associated mortality will not be effective without direct interventions on these factors including population based investigations on the distribution of and interactions between risk factors, sensitisation, and strengthening awareness of the general population on CVDs prevention needs [7-10]. Although a majority of CVD risk factors are well known and established, the variability of the individual contribution of each risk factor in different 
communities and ethnic groups, as well as the complexity of the management of CVD patients, necessitates the conduction of specific regional and subregional surveys, worldwide.

Data on the distribution of cardiovascular risk factors in the Adamawa Region of Cameroon is insufficient, forming the basis for this work in investigating and collecting current data on cardiovascular disease risk factors in Ngaoundéré, the principal town of the region, with the aim of contributing to the reduction of cardiovascular risk and prevention of CVDs.

\section{Study Area}

Our survey was carried out in Ngaoundéré, the headquarter of the Adamawa Region (Figure 1). This region shares boundaries in the south and north with the centre and north regions of Cameroon, respectively, in the west with Nigeria, and in the east with the Central African Republic. It is found in the high altitude guinea savannah ecological zone of Cameroon, possessing a surface area of $62000 \mathrm{~km}^{2}$, and is characterised by two seasons: a rainy season spanning the period from April to October and a dry season from November to March [11]. The main economic activity in the region is dairy farming and agriculture.

Ngaoundéré town comprises three subdivisions. The main health structure is the Ngaoundéré Regional Hospital which is public, followed by a private protestant hospital. There are also one subdivisional medical centre, one social medical centre at the Ngaoundéré University, four integrated health centres, and many private health centres. The population is made up of several ethnic groups of unequal proportions and distribution among which are the Foulbes, the Bororo, the Haoussas, the Gbaya, the Tikar, the Mboum, and the Dii.

\section{Methods}

3.1. Study Design, Subjects, and Selection Criteria. We conducted a prospective cross-sectional community-based survey from March to August 2014. We enrolled persons at least 18 years of age who resided in the study area for at least two years and who provided written consent to participate in the survey. Pregnant women and seriously sick persons (bedridden or in terminal phase of chronic disease) were not included in our study.

3.2. Sample Size. The sample size was calculated according to the following Lorenz formula:

$$
N=\frac{t^{2} \times p(1-p)}{m^{2}},
$$

where $N$ is the required sample size, $t$ is $Z$-score, in our case 1.96 for $95 \%$ confidence level, $p$ is the estimated prevalence of the risk factor in the survey zone, and $m$ is the error margin, in our case 0.05 for $5 \%$.

3.3. Sampling Method. We performed a two-stage sampling procedure wherein the quarters within the three subdivisions of the town were initially stratified following socioeconomic characteristics (low, middle, and high class and university area, considering majority of inhabitants). At least one quarter was selected from each subdivision to approximately represent the overall socioeconomic quotas; thus, 7 quarters have been selected. Secondly, households were selected within each quarter using a systematic method where every $K$ th household was selected beginning with that of the quarter head until the allocated number of participants per quarter attended. The calculated value of $K$ varied depending on the average number of households and inhabitants per household in each quarter. Seven quarters were selected and sensitised with the help of quarter head messengers and community relay workers prior to data collection, after which 100 participants were recruited per quarter.

3.4. Sample and Data Collection Procedure. In the course of our study, all adults per households visited who fulfilled eligibility criteria of the study were enrolled without any discrimination upon their gender or religious, ethnic, or social status. All data were collected and measurements performed in the evenings from 4 p.m. to $6 \mathrm{p} . \mathrm{m}$. at the participant's residence except for fasting blood glucose (FBG) which was measured between 6 a.m. and 9 a.m. the following morning for the same participants from whom data were collected the day before. Participants who could not communicate in French were assisted with translations to the Fulfulde (local) dialect which is widely spoken in the region. We prepared and pretested a semistructured questionnaire with which information on sociodemographics and several epidemiological factors and determinants of cardiovascular disease was collected.

\subsection{Measured Variables}

3.5.1. Blood Pressure (BP). Arterial blood pressure was measured with the help of a manual mercury sphygmomanometer (ADC Prosphyg model 770) according to the STEPS method described by the WHO [12]. This was performed following a 15-minute rest period, with the individual assuming a sitting position and on both arms, and having an average time lapse of 3 to 5 minutes between paired measurements. Arterial blood pressure measurements of $140 / 90 \mathrm{mmHg}$ or higher were considered as high blood pressure and results were recorded. Participants with high blood pressure measurements were referred for consultation with a cardiologist for comprehensive examination including other risk factors out of the scope of our study.

3.5.2. Fasting Blood Glucose (FBG). Fasting blood glucose levels were equally measured following WHO recommendations after an 8-12-hour overnight fast, using a glucometer (Accu-Chek ${ }^{\circledR}$ Performa). Hyperglycaemia was defined according to the WHO threshold [12], with measurements being greater than $1.26 \mathrm{~g} / \mathrm{dL}$.

3.5.3. Weight. We measured participants' weights using a mechanical balance (mark: SECA), with light weight clothing 


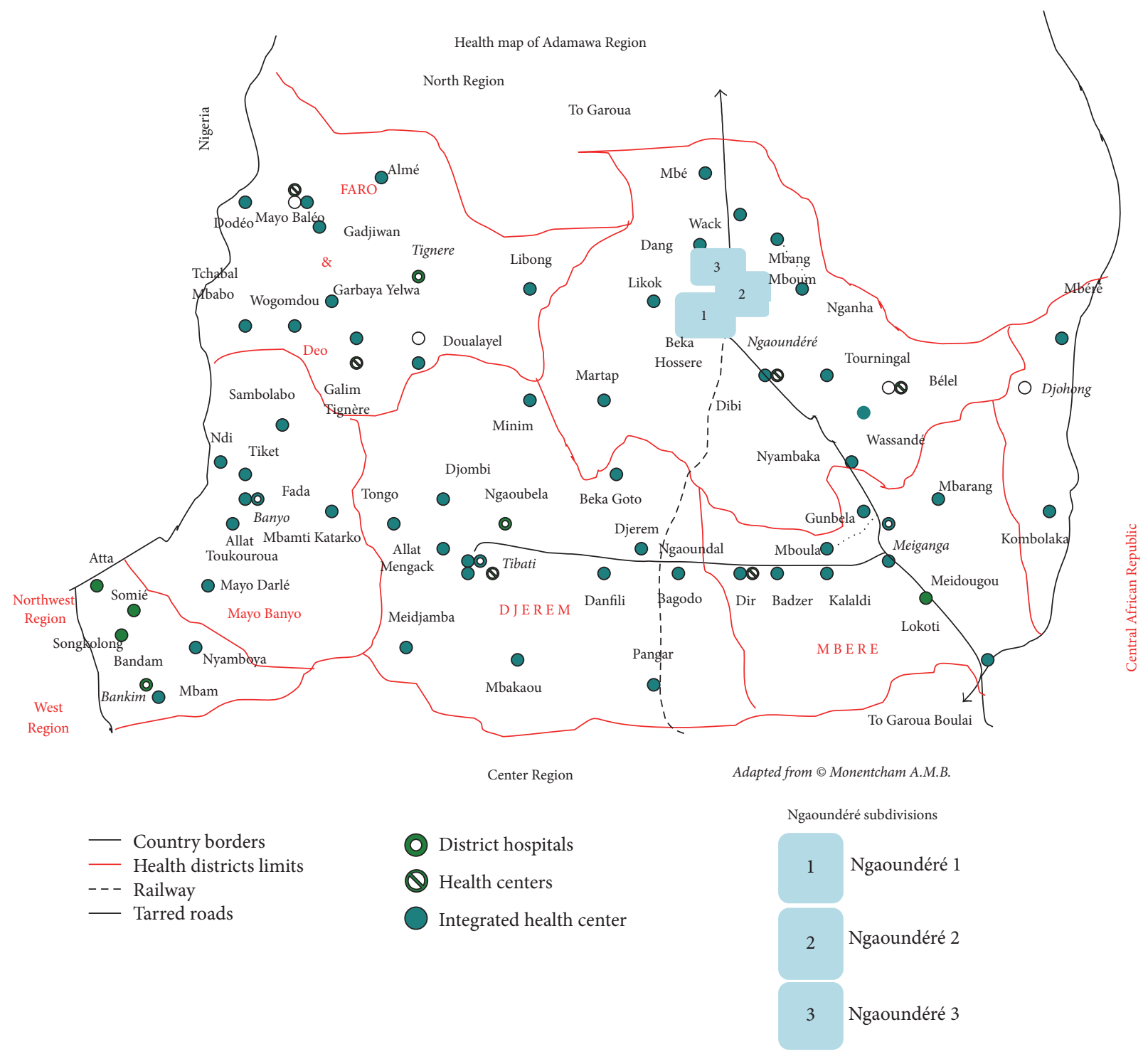

Figure 1: Map of the Adamawa Region of Cameroon, Africa.

and ensuring that the scale was on a flat and stable surface. The measurement of the body weight was done in conformity with the WHO STEPS method [12].

3.5.4. Height. Height measurements were done using a graduated flexible nonextensible ribbon tape (Gulick Measuring Tape(C) provided with a spring enabling the adjustment of the tension applied during measurement and having a precision of $0.1 \mathrm{~cm}$. These measurements were done in accordance with the WHO recommendations [12].

3.5.5. Body Mass Index (BMI). Body mass indices were calculated using formula BMI = weight $(\mathrm{kg}) /$ height $\left(\mathrm{m}^{2}\right)$. WHO thresholds were used to define general obesity, with $\mathrm{BMI} \geq 30$. Overweight was considered as BMI between 25 and
29 and underweight $\mathrm{BMI}<18.5$. BMI values between 18.5 and 24.9 were considered normal [13].

3.5.6. Waist Circumference Measurement. Waist circumference as an indicator of abdominal obesity was measured in accordance with the WHO STEPS method using a graduated flexible nonextensible ribbon tape (see height measurement)

3.6. Ethical Considerations. The authorisation to carry out this survey was obtained from the Adamawa Regional Delegation of Public Health (ref. N ${ }^{\circ} 507 / \mathrm{L} / \mathrm{HN} / \mathrm{DRSPA} / \mathrm{SAGE} /$ $\mathrm{BPF} / \mathrm{NGD}$ ) and the Ethical Committee of the Ngaoundéré Regional Hospital (ref. $N^{\circ} 1233 / \mathrm{L} / \mathrm{RC} / \mathrm{RA} / \mathrm{DSP} / \mathrm{HR} / \mathrm{NGD} /$ CLE). Participants provided written consent after obtaining information on the nature of the study and its merits and demerits. Specimen collection was performed under aseptic 
conditions and participant information was handled confidentially. Results per quarter were kept in the corresponding health centres, to be handed to the individual participants by the chief of the centre while ensuring proper referral for those with abnormal values.

3.7. Data Management, Analysis, and Interpretation of Results. All the data collected on the individual record sheet of participants were transferred onto an Excel spreadsheet. The confidentiality of the data was respected by minimising access to the data using a password. The saved data were verified with participants' individual record sheets for conformity and consistency. The data were finally forwarded onto SAS software version 9.1 for analysis with statistical significance stated at $p<0.05$.

\section{Results}

4.1. Basic Characteristics of the Study Population. Our survey population was made of 700 adults, with an age range of 18 to 93 years and average age of $36 \pm 17$ years. Among them were $340(48.6 \%)$ men and 360 (51.4\%) women. Two-thirds of this population were made up of Muslims and a third of Christians. The majority of our population were housewives (32\%) and were predominantly possessing secondary level education (41.1\%). With respect to participants with more than secondary education, women were less educated than men $(9.1 \%$ against $16.9 \%)$.

\subsection{Distribution of Cardiovascular \\ Disease (CVD) Risk Factors}

4.2.1. High Blood Pressure. A total of 143 (20.43\%) of the study participants had BP values above the normal, comprising $9.57 \%$ men and $10.86 \%$ women. The prevalence of higherthan-normal BP was recorded as $19.71 \%$ and $21.1 \%$ among male and female participants, respectively. In individuals under the age of 30 years, $9.40 \%$ presented higher-thannormal blood pressure and likewise 9.76\%, 27.59\%, and $45.03 \%$ in the age groups $30-39$ years, $40-49$ years, and $>50$ years, respectively. Although wide differences were observed between subgroup population weights, divorced persons (53.33\%) had the highest frequency of high blood pressure followed by married participants (25.0\%). Subpopulation proportions of participants with high BP were the highest among the unemployed (34.29\%), followed by household workers (29.91\%), and were the least among civil servants (6.19\%). Furthermore, frequency distributions of high blood pressure following educational level were performed and it was observed that $87.02 \%$ of persons with higher-thannormal blood pressure possessed at most a secondary level of education. The distributions of high blood pressure following sociodemographic characteristics are presented in Table 1.

4.2.2. Obesity and Overweight. Overall, $21.14 \%$ of the participants were overweight and $9.57 \%$ of the individuals were obese (Figure 2). The distribution of obesity according to

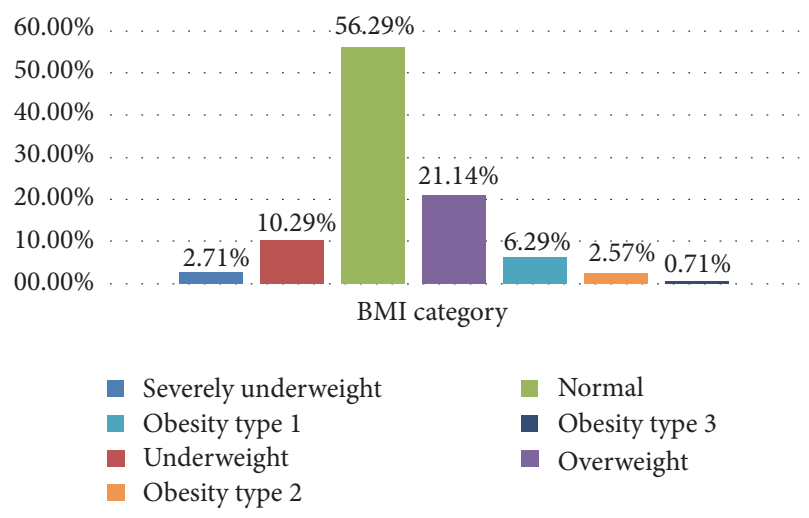

FIGURE 2: Distribution of study participants by BMI categories.

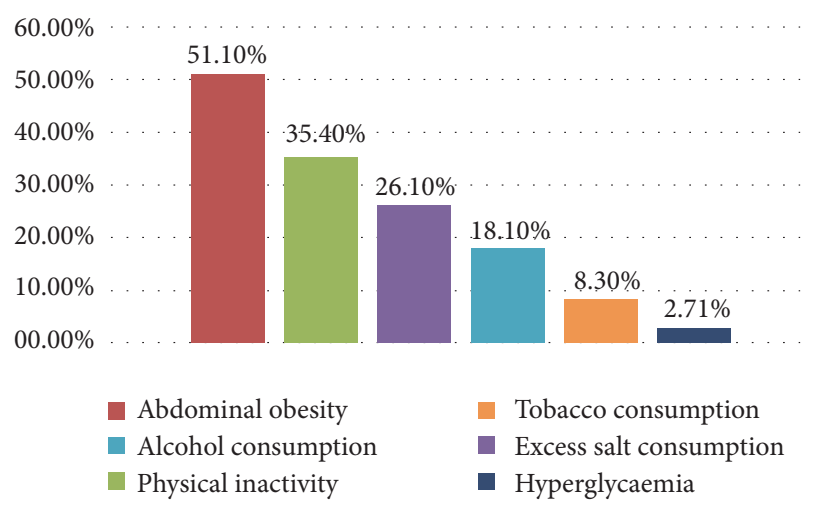

FIgURE 3: Distribution of other CVD risk factors in the study population.

gender showed a prevalence of $3.29 \%$ among men and $6.28 \%$ among women.

4.2.3. Other CVD Risk Factors. The other CVD risk factors we studied include hyperglycaemia, abdominal obesity, physical inactivity, and excess salt, alcohol, and tobacco consumption. Among these, physical inactivity (35.4\%) was highly prevalent, second only to abdominal obesity (51.1\%). Hyperglycaemia was the least present in our study population (Figure 3).

Gender based distributions demonstrated high frequencies of abdominal obesity, physical inactivity, and excess salt and alcohol consumption in women relative to men, while higher proportions of the male population were smokers and hyperglycaemic subjects (Figure 4).

4.2.4. Notion of Family History and Hereditary Diabetes, Arterial Hypertension, and Obesity. The possibility for hereditary hypertension, diabetes, and obesity was defined and constituted persons with raised BP (paired), FBG, and BMI measurements, having family history (at least a parent or sibling diagnosed) of hypertension, diabetes, and obesity, respectively. The probability of hereditary (familial) hypertension, diabetes (using hyperglycaemia), and obesity was 
TABLE 1: Distribution of high blood pressure by age, marital status, and gender.

\begin{tabular}{|c|c|c|c|c|c|}
\hline \multirow{2}{*}{ Variable } & \multirow{2}{*}{ Total, $n$} & \multicolumn{4}{|c|}{ High blood pressure } \\
\hline & & Men, $n(\%)$ & Women, $n(\%)$ & Total, $n(\%)$ & Proportion of the study population (\%) \\
\hline \multicolumn{6}{|l|}{ Age (years) } \\
\hline$<30$ & 319 & $18(5.64)$ & $12(3.76)$ & $30(9.40)$ & 4.29 \\
\hline $30-39$ & 123 & $2(1.63)$ & $10(8.13)$ & $12(9.76)$ & 1.71 \\
\hline $40-49$ & 87 & $13(14.94)$ & $11(12.64)$ & $24(27.59)$ & 3.43 \\
\hline$\geq 50$ & 171 & $34(19.88)$ & $43(25.15)$ & $77(45.03)$ & 11.00 \\
\hline \multicolumn{6}{|l|}{ Marital status } \\
\hline Unmarried & 253 & $16(6.32)$ & $10(3.95)$ & $26(10.28)$ & 3.71 \\
\hline Married & 426 & $46(10.80)$ & $59(13.85)$ & $105(24.65)$ & 15.00 \\
\hline Widowed & 6 & $3(50.00)$ & $1(16.67)$ & $4(66.67)$ & 0.57 \\
\hline Divorced & 15 & $2(13.33)$ & $6(40.00)$ & $8(53.33)$ & 1.14 \\
\hline \multicolumn{6}{|l|}{ Profession } \\
\hline Farmers & 34 & $2(5.88)$ & $2(5.88)$ & $4(11.76)$ & 0.57 \\
\hline Drivers & 26 & $5(19.23)$ & $0(0.00)$ & $5(19.23)$ & 0.71 \\
\hline Traders & 139 & $19(13.67)$ & $3(2.16)$ & $22(15.83)$ & 0.03 \\
\hline Students & 125 & $9(7.20)$ & $7(5.60)$ & $16(12.80)$ & 2.28 \\
\hline Household workers & 224 & $22(9.82)$ & $45(20.09)$ & $67(29.91)$ & 9.57 \\
\hline Civil servants & 117 & $0(0.00)$ & $7(5.98)$ & $7(6.19)$ & 1.00 \\
\hline Unemployed & 35 & $10(28.57)$ & $2(5.71)$ & $12(34.29)$ & 1.71 \\
\hline \multicolumn{6}{|l|}{ Level of education } \\
\hline Uneducated & 92 & $3(3.26)$ & $8(8.70)$ & $11(11.96)$ & 1.57 \\
\hline Coranic & 107 & $16(14.95)$ & $18(16.82)$ & $34(31.78)$ & 4.86 \\
\hline Primary & 121 & $8(6.61)$ & $20(16.53)$ & $28(23.14)$ & 4.00 \\
\hline Secondary & 288 & $32(11.11)$ & $26(9.03)$ & $58(20.14)$ & 8.29 \\
\hline Higher & 92 & $8(8.70)$ & $4(4.35)$ & $12(13.04)$ & 1.71 \\
\hline \multicolumn{6}{|l|}{ Religion } \\
\hline Atheist & 2 & $0(0.00)$ & $0(0.00)$ & $0(0.00)$ & 0.00 \\
\hline Christian & 235 & $17(7.23)$ & $18(7.66)$ & 35 (14.89) & 5.00 \\
\hline Muslim & 463 & $50(10.80)$ & $58(12.53)$ & $108(23.33)$ & 15.42 \\
\hline
\end{tabular}

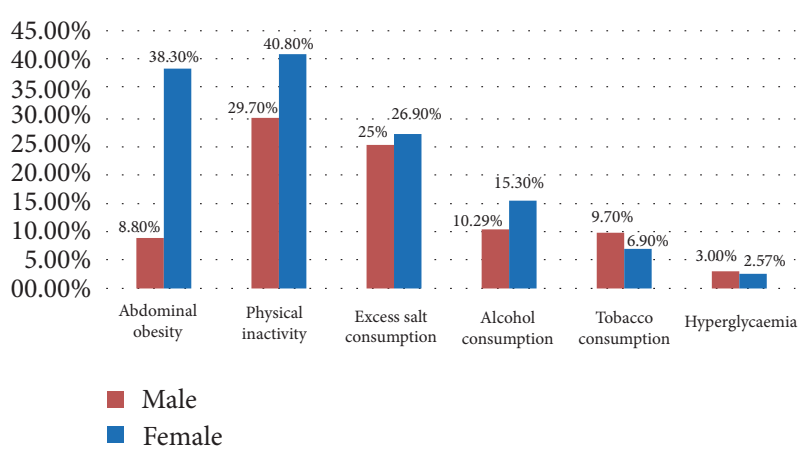

FIGURE 4: Distribution of other CVD risk factors by gender.

thus estimated at $11.6 \%, 11.28 \%$, and $4.6 \%$, respectively, in our survey.

4.3. Factors Associated with Hypertension. Based on blood pressure measurements and following JNC-7 recommendations [14], normotensive, prehypertensive, and hypertensive persons were estimated at $67.43 \%, 12.14 \%$, and $20.43 \%$.
Examining the distribution of high BP between other categories of CVD risk factors, hyperglycaemic persons (46.15\%) exhibited the highest prevalence of high BP followed by obese participants (31.34\%) and then tobacco consumers $(25.86 \%)$ as shown in Table 2.

Regression analysis proved that advanced age, alcohol consumption, hyperglycaemia, and a divorced marital status were associated with hypertension. Participants aged 40 to 49 $(\mathrm{OR}=3.83 ; p=0.0016)$ and 50 years and above $(\mathrm{OR}=7.08$; $p<0.0001)$ were more likely to have high BP values compared to those under 30 years of age. Likewise, participants with hyperglycaemia compared to normoglycaemia $(\mathrm{OR}=$ 4.2; $p=0.027)$ and those divorced compared to unmarried ones $(\mathrm{OR}=4.11 ; p=0.0488)$ were more prone to high blood pressure values, while alcohol consumers compared to nonconsumers were less likely to have high BP levels $(\mathrm{OR}=$ $0.16 ; p=0.0025)($ Table 3$)$.

\section{Discussion}

Except for some hospital studies involving a reduced number of participants and usually focussed on only one risk factor, 
TABLE 2: Distribution of High BP between other CVD risk factors and gender.

\begin{tabular}{lccccc}
\hline CVD risk factors & \multirow{2}{*}{ Total, $n$} & \multicolumn{3}{c}{ High blood pressure } \\
& & Men, $n(\%)$ & Women, $n(\%)$ & Total, $n(\%)$ & Proportion of study population (\%) \\
\hline Hyperglycaemia & 39 & $9(23.08)$ & $9(23.08)$ & $18(46.15)$ & 2.57 \\
Obesity & 67 & $15(22.39)$ & $6(8.96)$ & $21(31.34)$ & 3.00 \\
Alcohol consumption & 127 & $8(6.30)$ & $5(3.94)$ & $13(10.24)$ & 1.86 \\
Tobacco consumption & 58 & $7(12.07)$ & $8(13.79)$ & $15(25.86)$ & 2.14 \\
Physical inactivity & 248 & $21(8.47)$ & $38(15.32)$ & $59(23.79)$ & 8.43 \\
Excessive salt consumption & 182 & $12(6.59)$ & $24(13.19)$ & $36(19.78)$ & 5.14 \\
\hline
\end{tabular}

TABLE 3: Logistic regression for HBP with other CVD risk factors.

\begin{tabular}{|c|c|c|c|}
\hline Variables & $p$ value & Odds ratio & {$[95 \% \mathrm{CI}]$} \\
\hline \multicolumn{4}{|l|}{ Age group } \\
\hline$<30$ & Reference & 1 & \\
\hline $30-39$ & 0.8419 & 0.91 & {$[0.36-2.2]$} \\
\hline $40-49$ & $0.0016^{* *}$ & 3.83 & {$[1.66-8.9]$} \\
\hline$\geq 50$ & $<0.0001^{* * *}$ & 7.08 & [3.43-15.2] \\
\hline \multicolumn{4}{|l|}{ Sex } \\
\hline Male & Reference & 1 & \\
\hline Female & 0.6820 & 0.77 & {$[0.35-1.68]$} \\
\hline \multicolumn{4}{|l|}{ Obesity } \\
\hline No & Reference & 1 & \\
\hline Yes & 0.0881 & 1.04 & [0.049-0.22] \\
\hline \multicolumn{4}{|c|}{ Alcohol consumption } \\
\hline No & Reference & 1 & \\
\hline Yes & $0.0025^{* *}$ & 0.16 & [0.046-0.49] \\
\hline \multicolumn{4}{|c|}{ Tobacco consumption } \\
\hline No & Reference & 1 & \\
\hline Yes & 0.0561 & 2.26 & {$[0.95-5.18]$} \\
\hline \multicolumn{4}{|c|}{ Physical inactivity } \\
\hline No & Reference & 1 & \\
\hline Yes & 0.3680 & 1.03 & {$[0.28-3.70]$} \\
\hline \multicolumn{4}{|l|}{$\begin{array}{l}\text { Excessive salt } \\
\text { consumption }\end{array}$} \\
\hline No & Reference & 1 & \\
\hline Yes & 0.1450 & 1.05 & {$[0.52-2.07]$} \\
\hline \multicolumn{4}{|c|}{ Hyperglycaemia } \\
\hline No & Reference & 1 & \\
\hline Yes & $0.0270^{*}$ & 4.20 & {$[1.17-15.2]$} \\
\hline \multicolumn{4}{|l|}{ Marital status } \\
\hline Unmarried & Reference & 1 & \\
\hline Divorced & $0.0488^{*}$ & 4.11 & {$[0.92-18.3]$} \\
\hline Married & 0.8634 & 0.80 & [0.39-1.62] \\
\hline Widowed & 0.7964 & 1.2 & {$[0.13-12.5]$} \\
\hline
\end{tabular}

${ }^{* * *} p<0.001 ;^{* *} p<0.01 ;{ }^{*} p<0.05$.

few epidemiological data are available quantifying cardiovascular disease risk factors in northern regions of Cameroon. This community survey carried out in Ngaoundéré town was aimed at studying cardiovascular disease risk factors and their association with hypertension so as to contribute to the improvement of disease prevention, control, and management.

\subsection{The Prevalence of Cardiovascular Disease Risk Factors}

5.1.1. Arterial Hypertension. Our study showed that approximately one-fifth (20.43\%) of the study participants had arterial blood pressure values higher than normal at the time of measurement. Data from a 2004 study by Kengne et al. reported similar rates (20.8\%) in Cameroon [15]. Studying a ten-year variation in hypertension in Cameroon, Fezeu et al. (2010) suggested a 2- to 5-fold increase in both urban and rural dwellers of both sexes [16]. The distribution of hypertension in sub-Saharan Africa varies considerably between countries with recent surveys reporting occurrence rates of $27.9 \%$ in Ethiopia [17], 31.8\% in Nigeria [18], and $47 \%$ in Kenya [19], among others. As previously proposed by other authors, we acknowledge the contribution of socioeconomic, environmental, and behavioural determinants to this prevalence, including increasing economic growth and urbanisation, consumption of tobacco and fatty foods, and long periods of risk exposure to these factors due to a longlife experience $[20,21]$.

5.1.2. Overweight and Obesity. Overweight and obesity were estimated in $21.14 \%$ and $9.57 \%$ of the study population, respectively, values which are lower than the $23.7 \%$ and $11.1 \%$ previously reported in Cameroon [15]. Although our results recorded the prevalence of overweight and obesity lower than the $34.5 \%$ and $9.5 \%$ observed in Kenya [22], 28.2\% and $13.8 \%$ in Nigeria [18], and $29.6 \%$ and $13.0 \%$ in Iran [23], respectively, they remain far below the $72.4 \%$ recorded in South Africa in 2013 [24]. Gender based distribution of obesity portrayed women $(6.28 \%)$ to be more affected by obesity than men (3.29\%), concurring with previous findings $[17,19,23]$. Our results differ greatly and are much lower than those reported in Western Europe (France: $6.28 \%$ in men and $37 \%$ in women) and Asia (China: $45 \%$ in men and $32 \%$ in women) [25]. These differences could be explained by the improved living standards, advanced state of urbanisation, and other inherent sociocultural attributes associated with the latter region.

In addition, we observed that abdominal obesity occurred in about half of our participants $(51.1 \%)$ in the study. Kengne and coworkers reported $14 \%$ and $59.5 \%$ prevalence 
of abdominal obesity in urban dwelling Cameroonian men and women, respectively [15]. Our rate, despite being in line with the reports of Elasmi et al. (2009) in the Grand Tunis population [26], is far higher than the $14.4 \%$ observed in Iran [23] and is possibly the result of an increase in the consumption of salts and fatty and energy-rich foods with deprivation in vitamins and mineral salts due to the change in lifestyle habits [27].

5.1.3. Hyperglycaemia. Hyperglycaemia was defined as an increase in blood glucose level above $1.26 \mathrm{~g} / \mathrm{dL}$ measured after an overnight fast of 8 to 12 hours with or without any associated clinical manifestations. The prevalence of hyperglycaemia was $5.57 \%$ in our survey (3\% in men and $2.57 \%$ in women). Diabetes mellitus has been reported to occur in about $2.9 \%$ to $6.2 \%$ of Cameroon's rural and urban subpopulations [28], similar to the observed 3.6\% in neighbouring Nigeria [18]. This is lower than the results reported in several countries: $11.9 \%$ in men and $11.7 \%$ in women in South Africa [24], 7.8\% in men and $8.5 \%$ in women in Congo [29], $7.2 \%$ in men and $4.3 \%$ in women in France, and $12.6 \%$ in men and $9.1 \%$ in women in the United States [30]. Probably, our sampling methods could have led to underestimation of the occurrence of hyperglycaemia in our study population as we did not consider diabetic patients on treatment and having normal FBG levels as being hyperglycaemic contrary to the other authors $[26,29]$.

\subsection{Other Cardiovascular Disease Risk Factors}

5.2.1. Tobacco and Alcohol. The prevalence of alcohol and tobacco consumption in our survey was $18.1 \%$ and $8.3 \%$, respectively, with even much lesser rates reported in rural Kenya [19], findings which are lower than the previously reported $85 \%$ and $16 \%$ in urban Cameroon [16] and $55.8 \%$ and $13 \%$ in Nigeria [18]. The prevalence of these two risk factors varies between countries with an unequal distribution between men and women $[17,22]$. Inherent sociocultural and economic factors possibly affect these habits in our setting such as the state of reduced urbanisation and the widely practiced Muslim faith.

5.2.2. Excessive Salt Consumption. $26.1 \%$ of participants consumed large quantities of salt, which is encouraged by several sociocultural practices. The high consumption of sodium is common in Kenya due to the use of salts to preserve food or render it appetising or to be added to prepared food by consumers [19]. These facts were reflected in our work as several participants from different quarters of the town were observed to consume a large quantity of salts.

5.2.3. Sedentary Lifestyle. Compared to the $35.4 \%$ proportion of our participants characterised with a sedentary lifestyle, other African studies have reported relatively higher values of $52.2 \%$ [24] and $42.6 \%$ [29]. This is likely owing to the fact that animal breeding and farming which are most practiced in this region necessitate important geographical displacement. In our study, however, physical inactivity appeared to be a more dominant risk factor for cardiovascular diseases compared to high blood pressure, thus contradicting reports of other subSaharan studies in which arterial hypertension was observed to be the most prevalent CVD risk factor $[22,30]$.

5.2.4. Hereditary Hypertension, Diabetes, and Obesity. The probability of family heredity of arterial hypertension was found in $11.6 \%$ of the study population and likewise $11.28 \%$ and $4.6 \%$ for diabetes and obesity, respectively. It has been clearly established in previous studies that family history of arterial hypertension is associated with a significant risk of hypertension for both men and women [31]. Our results therefore suggest a relatively high medium- to long-term risk of hypertension in our population.

5.3. Factors Associated with Arterial Hypertension. Previous reports have established the role of advanced age as a risk factor for hypertension [17, 24, 32]. A study carried out in Israel between 2002 and 2007 showed that ten years caused a 1.6-fold rise in the risk of being in a higher JNC-7 category of blood pressure [33]. Regression analysis reiterated the relationship between advanced age and arterial hypertension, as the likelihood of high blood pressure was 3.8 -fold ( $p=$ $0.0016)$ and 7.1-fold $(p<0.0001)$ the normal for participants aged 40-49 and 50 years and above, respectively, compared to those 30 years of age and below.

Hyperglycaemia is another CVD risk factor which demonstrated an association with hypertension in this study. $46.15 \%$ of the participants with raised fasting blood sugar levels had higher-than-normal blood pressure values. These findings are in conformity with the previous literature [34].

Alcohol consumption was inversely associated with arterial blood pressure: consumers of alcohol were less likely to have high BP values compared to nonconsumers ( $p=0.0025$; $\mathrm{OR}=0.16)$. These results are similar to those obtained by Peltzer and Phaswana-Mafuya [24], although other studies hold the notion that the consumption of even very little quantities of alcohol increases the risk of hypertension [35, 36].

5.4. Limitations of This Study. This study was characterised with several limitations with the most significant being the reliability of data analysis based on nonverifiable verbal responses of participants. Also, the evaluation of alcohol and tobacco consumption was incoherent as several participants consumed tobacco in powder form by chewing and others consumed local alcoholic beverages rendering quantification difficult. Lastly, the time frame within which our study was carried out did not permit an elaborate investigation on dietary awareness, patterns, and practice as a function of CVD risk at individual level within the population.

5.5. Conclusion. Our study on cardiovascular diseases risk factors indicates relatively high occurrences of several factors within the Ngaoundéré community with dominant risk factors being abdominal obesity, physical inactivity, excessive salt consumption, arterial hypertension, and alcohol consumption. Furthermore, advanced age, hyperglycaemia, 
a divorced marital status, and consumption of alcohol were associated with higher-than-normal blood pressure levels.

5.6. Perspectives. This study was carried out in an urban setting within the Adamawa Region where access to health information, services, and promotion programs and socioeconomic and educational levels are relatively higher compared to rural settlements. It is imperative therefore for future studies to be carried in rural communities of the Adamawa Region as well as comparative studies between regions of the Cameroon national territory. This will furnish relevant data necessary for informed decision-making, advocacy, elaboration of health promotion programs, and strengthening the health system in a bid to progressively and sufficiently prevent, control, and manage cardiovascular diseases nationwide.

\section{Competing Interests}

The authors declare that they have no competing interests.

\section{Acknowledgments}

The authors express immense gratitude to Pr. Elias Nchiwan Nukenine for the supervision of this research work. They also extend their gratitude to all the participants for their enthusiasm and the interest they accorded in this research work. They equally extend gratitude to the Adamawa public health regional delegate, the staff of the corresponding district health services, health centres, community relay workers, and the local community rulers for their monumental collaboration throughout this survey.

\section{References}

[1] I. C. Bygbjerg, "Double burden of noncommunicable and infectious diseases in developing countries," Science, vol. 337, no. 6101, pp. 1499-1501, 2012.

[2] M. Naghavi, H. Wang, R. Lozano et al., "Global, regional, and national age-sex specific all-cause and cause-specific mortality for 240 causes of death, 1990-2013: a systematic analysis for the Global Burden of Disease Study 2013," The Lancet, vol. 385, no. 9963, pp. 117-171, 2015.

[3] M. Ezzati, A. D. Lopez, A. Rodgers, S. V. Hoorn, and C. J. L. Murray, "Selected major risk factors and global and regional burden of disease," The Lancet, vol. 360, no. 9343, pp. 1347-1360, 2002.

[4] S. Mendis, T. Armstrong, D. Bettcher et al., Global Status Report on Noncommunicable Diseases 2014, WHO Library Cataloguing-in-Publication Data, Geneva, Switzerland, 2014.

[5] WHO, Global Atlas on Cardiovascular Disease Prevention and Control, World Health Organization, Geneva, Switzerland, 2011.

[6] World Health Organization, Noncommunicable Diseases Country Profiles 2014, WHO Library Cataloguing-in-Publication Data, Geneva, Switzerland, 2014.

[7] H. L. F. Kamga, N. J. C. Assob, D. S. Nsagha, A. L. Njunda, and D. L. Njimoh, "A community survey on the knowledge of neglected tropical diseases in Cameroon," International Journal of Medicine and Biomedical Research, vol. 1, no. 2, pp. 131-140, 2012.
[8] M. O. Pancha, A. M. N. Aïdego, M. T. Tamanji, and M. B. Atanga, "Educational needs of hypertensive patients in Buea hospital setting (Cameroon)," Health Science and Disease, vol. 16, no. 2, pp. 1-5, 2015.

[9] O. P. Mbouemboue, E. Yiagnigni, A. K. Koona, J. Cacko, and P. Ndobo, "Determinants of hypertension awareness and treatment among patients under cardiology follow-up in A Cameroonian Regional Hospital," International Journal of Collaborative Research on Internal Medicine \& Public Health, vol. 4, no. 9, pp. 1663-1672, 2012.

[10] P. K. Awah, A. P. Kengne, L. L. K. Fezeu, and J.-C. Mbanya, "Perceived risk factors of cardiovascular diseases and diabetes in Cameroon," Health Education Research, vol. 23, no. 4, pp. 612620, 2008.

[11] F. Tchuenguem Fohouo, S. Tope, A. Mbianda, J. Messi, and D. Bruckner, "Foraging behaviour of Apis mellifera adansonii Latreille (Hymenoptera : Apidae) on Daniellia oliveri, Delonix regia, Hymenocardia acida and Terminalia mantaly flowers in Ngaoundéré (Cameroon)," International Journal of Biological and Chemical Sciences, vol. 4, no. 4, pp. 1180-1190, 2011.

[12] World Health Organization, The WHO STEPwise Approach to Chronic Disease Risk Factor Surveillance/Non-Communicable Diseases and Mental Health, WHO, Geneva, Switzerland, 2005.

[13] WHO, Physical Status: The Use and Interpretation of Anthropometry. Report of a WHO Expert Committee. WHO Technical Report Series 854, World Health Organization, Geneva, Switzerland, 1995.

[14] A. V. Chobanian, G. L. Bakris, H. R. Black et al., "The Seventh Report of the Joint National Committee on Prevention, Detection, Evaluation, and Treatment of High Blood Pressure: the JNC 7 report," The Journal of the American Medical Association, vol. 289, no. 19, pp. 2560-2572, 2003.

[15] A. P. Kengne, P. K. Awah, L. Fezeu, and J. C. Mbanya, "The burden of high blood pressure and related risk factors in urban Sub-Saharan Africa: evidences from Douala in Cameroon," African Health Sciences, vol. 7, no. 1, pp. 38-44, 2007.

[16] L. Fezeu, A. P. Kengne, B. Balkau, P. K. Awah, and J. C. Mbanya, "Ten-year change in blood pressure levels and prevalence of hypertension in urban and rural Cameroon," Journal of Epidemiology and Community Health, vol. 64, no. 4, pp. 360365, 2010.

[17] S. M. Abebe, Y. Berhane, A. Worku, and A. Getachew, "Prevalence and associated factors of hypertension: a crossectional community based study in Northwest Ethiopia," PLOS ONE, vol. 10, no. 4, Article ID e0125210, 2015.

[18] O. S. Ogah, O. O. Madukwe, U. U. Onyeonoro et al., "Cardiovascular risk factors and non-communicable diseases in Abia state, Nigeria: report of a community-based survey," International Journal of Medicine \& Biomedical Research, vol. 2, no. 1, pp. 5768, 2013.

[19] J. Muchira, E. Stuart-Shor, J. Kariuki et al., "Distribution and characteristics of risk factors for cardiovascular-metabolic disease in a rural Kenyan community," International Journal of Africa Nursing Sciences, vol. 3, pp. 76-81, 2015.

[20] O. Steichen, "Hypertension artérielle du sujet noir," la Revue du Praticien, vol. 60, pp. 654-659, 2010.

[21] J. B. Echouffo-Tcheugui and A. P. Kengne, "Chronic noncommunicable diseases in Cameroon-burden, determinants and current policies," Globalization and Health, vol. 7, article no. 44, 2011.

[22] M. E. Hendriks, F. W. N. M. Wit, M. T. L. Roos et al., "Hypertension in Sub-Saharan Africa: cross-sectional surveys 
in four rural and urban communities," PLoS ONE, vol. 7, no. 3, Article ID e32638, 2012.

[23] H. Najafipour, G. Yousefzadeh, A. Forood, M. Karamouzian, M. Shadkam, and A. Mirzazadeh, "Overweight and obesity prevalence and its predictors in a general population: a communitybased study in Kerman, Iran (kerman coronary artery diseases risk factors studies)," ARYA Atherosclerosis, vol. 12, no. 1, pp. 1827, 2016

[24] K. Peltzer and N. Phaswana-Mafuya, "Hypertension and associated factors in older adults in South Africa," Cardiovascular Journal of Africa, vol. 24, no. 3, pp. 67-72, 2013.

[25] M. M. Finucane, G. A. Stevens, M. J. Cowan et al., "National, regional, and global trends in body-mass index since 1980: systematic analysis of health examination surveys and epidemiological studies with 960 country-years and 9.1 million participants," The Lancet, vol. 377, no. 9765, pp. 557-567, 2011.

[26] M. Elasmi, M. Feki, H. Sanhaji et al., "Prévalence des facteurs de risque cardiovasculaires conventionnels dans la population $\mathrm{du}$ Grand Tunis," Revue d'Épidémiologie et de Santé Publique, vol. 57, no. 2, pp. 87-92, 2009.

[27] N. Marion and M. N. Berkeley, "Why calories count: from science to politics," Health Affairs, vol. 31, no. 9, p. 2150, 2012.

[28] E. Sobngwi, J.-C. N. Mbanya, N. C. Unwin et al., "Physical activity and its relationship with obesity, hypertension and diabetes in urban and rural Cameroon," International Journal of Obesity, vol. 26, no. 7, pp. 1009-1016, 2002.

[29] A. Yahia-Berrouiguet, M. Benyoucef, K. Meguenni, and M. Brouri, "Prevalence of cardiovascular risk factors: a survey at Tlemcen (Algeria)," Medecine des Maladies Metaboliques, vol. 3, no. 3, pp. 313-319, 2009.

[30] S. Pessinaba, A. Mbaye, G. A. D. Yabéta et al., "Enquête de prévalence des facteurs de risque cardiovasculaire en population générale à Saint-Louis (Sénégal)," Annales de Cardiologie et d'Angéiologie, vol. 62, no. 4, pp. 253-258, 2013.

[31] E. Méndez-Chacón, C. Santamaría-Ulloa, and L. Rosero-Bixby, "Factors associated with hypertension prevalence, unawareness and treatment among Costa Rican elderly," BMC Public Health, vol. 8, no. 1, article 275, 2008.

[32] J. Kishore, N. Gupta, C. Kohli, and N. Kumar, "Prevalence of hypertension and determination of its risk factors in rural Delhi," International Journal of Hypertension, vol. 2016, Article ID 7962595, 6 pages, 2016.

[33] K. Abu-Saad, A. Chetrit, S. Eilat-Adar et al., "Blood pressure level and hypertension awareness and control differ by marital status, sex, and ethnicity: a population-based study," American Journal of Hypertension, vol. 27, no. 12, pp. 1511-1520, 2014.

[34] A. Dzudie, A. P. Kengne, W. F. T. Muna et al., "Prevalence, awareness, treatment and control of hypertension in a self-selected sub-Saharan African urban population: a crosssectional study," BMJ Open, vol. 2, no. 4, Article ID e001217, 2012.

[35] I. B. Puddey and L. J. Beilin, "Alcohol is bad for blood pressure," Clinical and Experimental Pharmacology and Physiology, vol. 33, no. 9, pp. 847-852, 2006.

[36] A. Briasoulis, V. Agarwal, and F. H. Messerli, "Alcohol consumption and the risk of hypertension in men and women: a systematic review and meta-analysis," Journal of Clinical Hypertension, vol. 14, no. 11, pp. 792-798, 2012. 


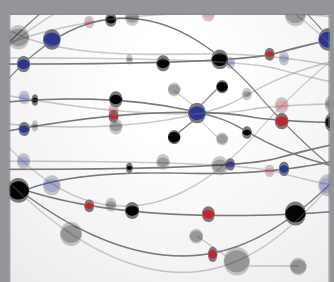

The Scientific World Journal
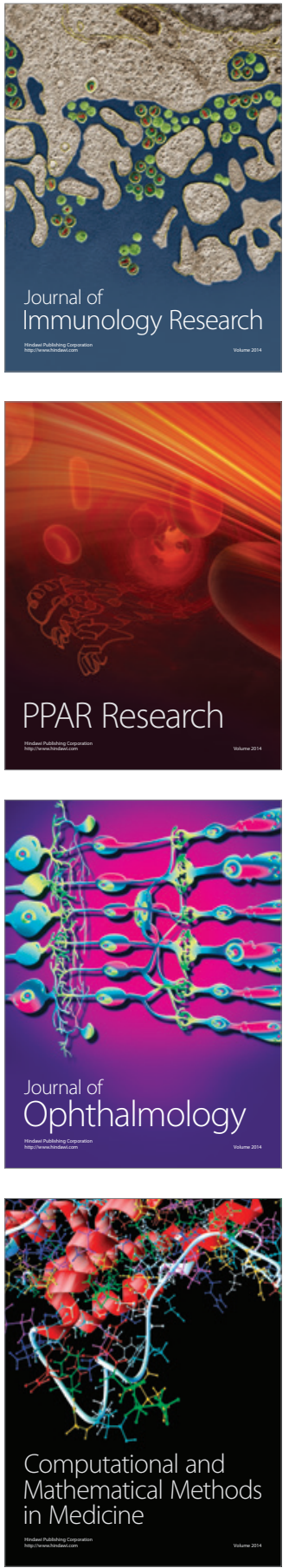

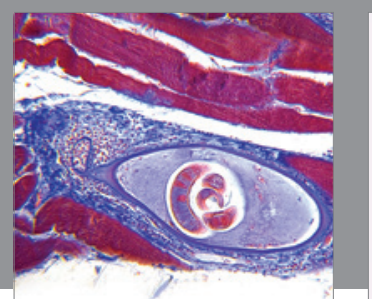

Gastroenterology Research and Practice

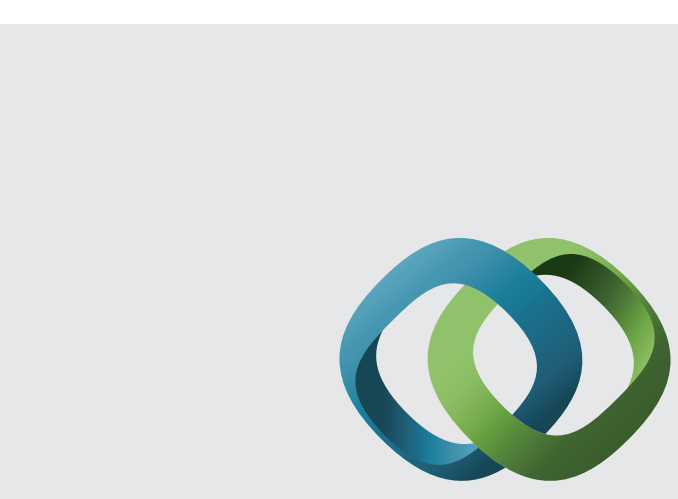

\section{Hindawi}

Submit your manuscripts at

http://www.hindawi.com
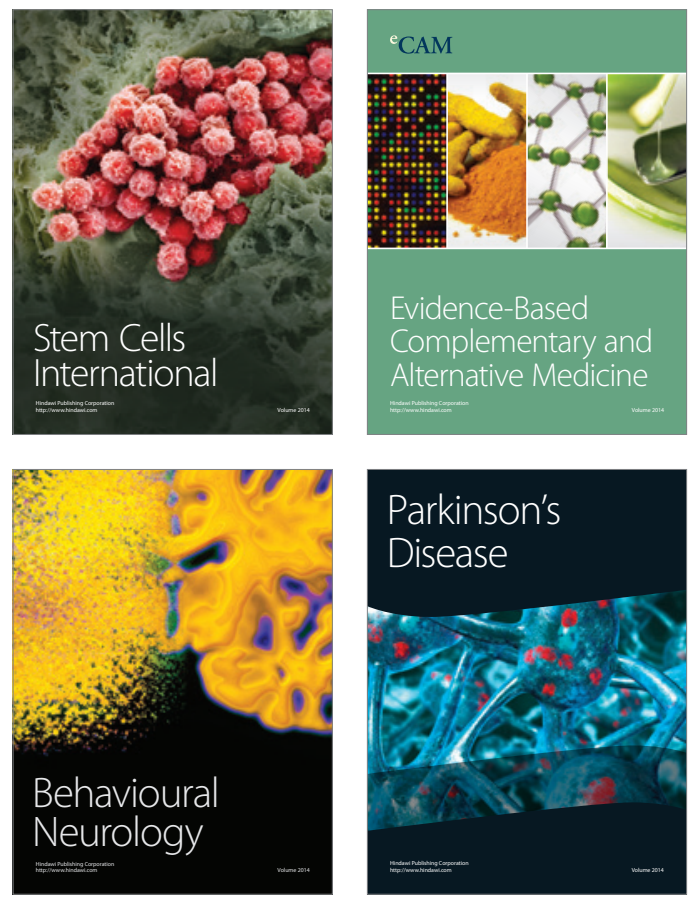
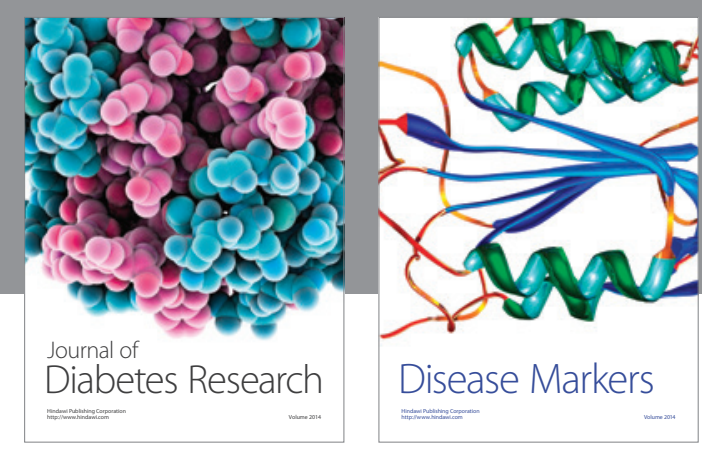

Disease Markers
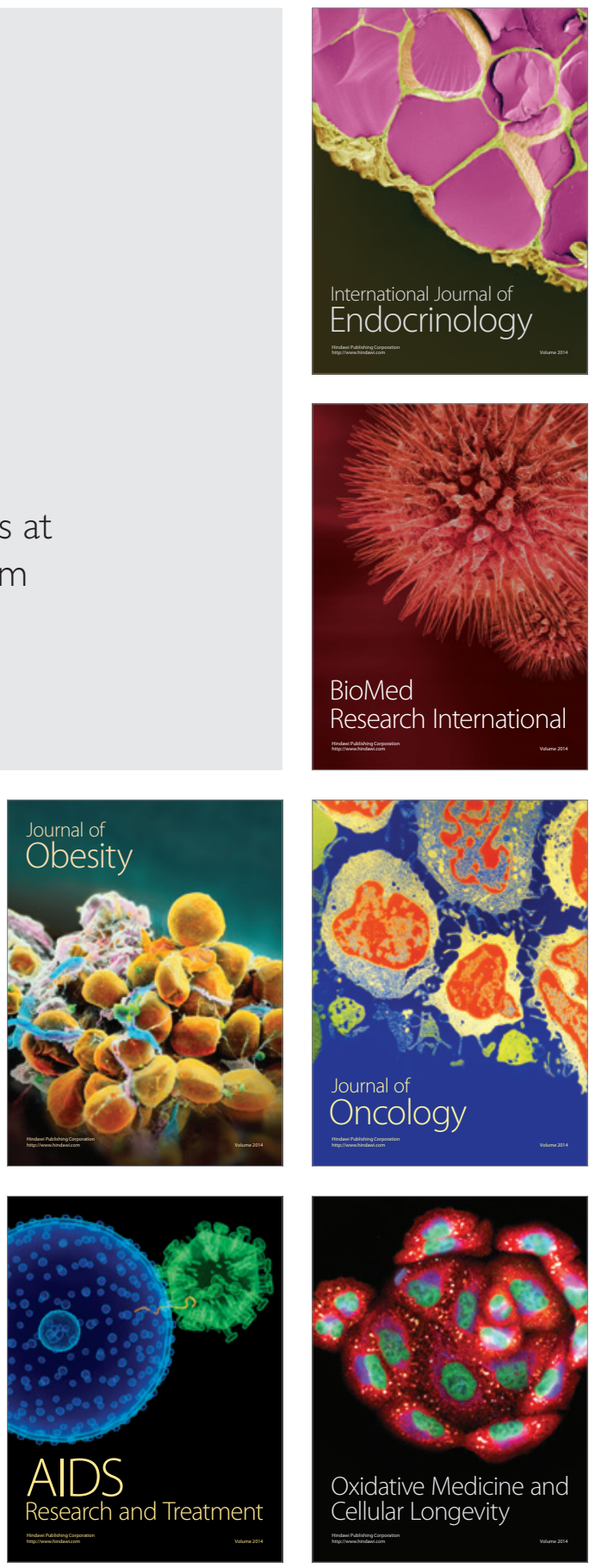